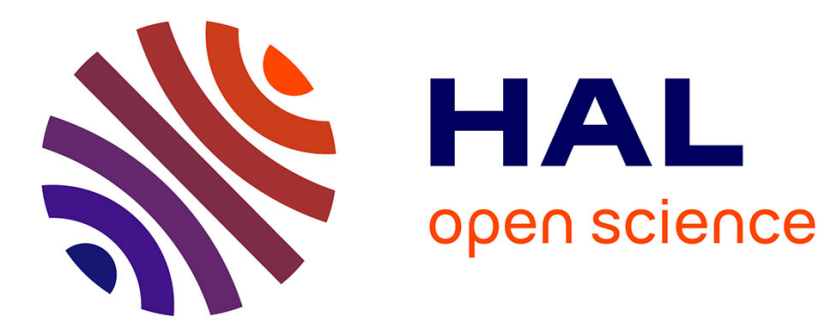

\title{
The social sharing of emotions in HIV/AIDS: A comparative study of HIV/AIDS, diabetic and cancer patients
}

Nicole Cantisano, Bernard Rimé, María Muñoz-Sastre

\section{- To cite this version:}

Nicole Cantisano, Bernard Rimé, María Muñoz-Sastre. The social sharing of emotions in HIV/AIDS: A comparative study of HIV/AIDS, diabetic and cancer patients. Journal of Health Psychology, 2012, 18 (10), pp.1255-1267. 10.1177/1359105312462436 . hal-02482243

HAL Id: hal-02482243

https://hal-univ-tlse2.archives-ouvertes.fr/hal-02482243

Submitted on 24 Apr 2020

HAL is a multi-disciplinary open access archive for the deposit and dissemination of scientific research documents, whether they are published or not. The documents may come from teaching and research institutions in France or abroad, or from public or private research centers.
L'archive ouverte pluridisciplinaire HAL, est destinée au dépôt et à la diffusion de documents scientifiques de niveau recherche, publiés ou non, émanant des établissements d'enseignement et de recherche français ou étrangers, des laboratoires publics ou privés. 


\section{Journal of}

Health Psychology

\section{The Social Sharing of emotions in HIV/AIDS: A comparative study of HIV/AIDS, Diabetes and Cancer Patients}

\begin{tabular}{|r|l|}
\hline Journal: & Journal of Health Psychology \\
\hline Manuscript ID: & JHP-12-0224.R2 \\
\hline Manuscript Type: & Article \\
\hline Keywords: & AIDS, CANCER, EMOTIONS, SOCIAL SUPPORT, HIV, STIGMATIZATION \\
\hline Abstract: & $\begin{array}{l}\text { Studies have shown that chronic illness patients encounter difficulties in } \\
\text { the Social Sharing of Emotions (SSE). Do HIV/AIDS patients present } \\
\text { distinguishing traits in the inhibition of illness and non-illness related } \\
\text { emotions? The differences in the SSE between 35 HIV/AIDS, 35 diabetes } \\
\text { and 34 cancer outpatients were studied. A questionnaire assessed illness- } \\
\text { related emotions, SSE and emotional inhibition. The HIV/AIDS group } \\
\text { significantly presented: superior scoring in shame, guilt and non-sharing of } \\
\text { illness-related emotions, lower frequencies of SSE and less sharing } \\
\text { partners. These findings could lead to future research examining the } \\
\text { emotional expression of guilt and shame in HIV/AIDS. }\end{array}$ \\
\hline \multicolumn{2}{|l}{} \\
\hline
\end{tabular}


Running head: SOCIAL SHARING OF EMOTIONS IN HIV/AIDS

The Social Sharing of emotions in HIV/AIDS: A comparative study of HIV/AIDS, Diabetes and Cancer Patients

Nicole Cantisano

Université de Toulouse II-Le Mirail, Laboratoire Octogone-Cerpp, Toulouse, France

Bernard Rimé

Université de Louvain, Institut de Recherche en Sciences Psychologiques, Louvain-la-Neuve, Belgium

María T. Muñoz-Sastre

Université de Toulouse II-Le Mirail, Laboratoire Octogone-Cerpp, Toulouse, France

Authors' notes

We thank the National HIV/AIDS/STI Control Program (DIGECITSS) of the Dominican Republic's Ministry of Health for their collaboration in the realization of this study. Correspondence concerning this article should be addressed to Nicole Cantisano, URI Octogone, Pavillon de la Recherche, Université de Toulouse II - Le Mirail, 5 allée Antonio Machado, Toulouse Cedex 9, 31058 France. Phone (+33)5-61-50-25-97. E-mail: cantisanonicole@gmail.com 


\section{SOCIAL SHARING OF EMOTIONS IN HIV/AIDS}

\section{The Social Sharing of Emotions in HIV/AIDS: A comparative study of HIV/AIDS, Diabetes and Cancer Patients}

\section{Introduction}

Previous research on the social aspects of emotional regulation has shown that individuals communicate their emotions. The propensity to speak and share emotional experiences has been thoroughly investigated and denoted as the Social Sharing of Emotions (SSE) (Rimé et al., 1991; Rimé et al., 1992; Rimé, 2009). SSE has been defined as "the evocation of an emotion by the means of socially shared language, at the presence, at least symbolic, of an addressee to whom the emotion is evoked" (Rimé, 2007 , p. 86). Evidence shows that $80 \%$ to $95 \%$ of emotional experiences, negative or positive, are object of SSE. This propensity to speak about emotional experiences is manifested during the hours, days, weeks or sometimes months following the emotional episode.

SSE studies have thoroughly supported that, following mayor life negative events, (e.g. Sydor \& Philippot, 1996) as well as daily life events (e.g., Rimé et al., 1991), people look for the company of others to share and talk about the emotioneliciting event (Rimé, 2009). Accordingly, SSE can result in positive outcomes both at inter- and intra- personal levels. As addressed by Rime et al. (1998), some of the benefits and functions served by the SSE are: (1) constructing and consolidating memory of important events, (2) processing and completing the emotional memory, (3) enhancing interpersonal relationships and social integration, and (4) constructing and disseminating social knowledge on emotion. On the one hand, at the interpersonal level, social sharing may bring forth emotional contagion, empathy, attachment and strengthened social ties between sharing persons and their listeners (Rimé, 2009; 


\section{SOCIAL SHARING OF EMOTIONS IN HIV/AIDS}

Christophe \& Rimé, 1997). On the other hand, at the intrapersonal level, SSE may result in cognitive benefits such as making meaning of the situation when the sharing mode takes place in a cognitive reappraisal fashion (Nils \& Rimé, 2012).

As raised by Lepore et al. (2000), talking about stressful experiences allows individuals to construct an organized narrative which becomes part of individuals' cognitive representation of the stressor. Therefore, succeeding the emotional impact linked to a physical illness, it is plausible to consider that SSE can provide a positive contribution to emotional adjustment as well as to social integration. For instance, previous research has shown that prostate cancer survivors who benefit from high quality social interactions cope better with cancer-related thoughts and present an enhanced mental health (Lepore \& Helgeson, 1998).

Research has shown that patients in general are quite eager to share their illnessrelated emotions. To illustrate, Cardiac patients anticipating surgery shared their emotional distress in 91\% of cases (Panagopoulou et al., 2006). However, previous research has also shown that chronic illness patients encounter emotional inhibition and difficulties in the social sharing of illness-related emotions. Herbette \& Rimé (2004) observed that chronic pain patients frequently inhibited their emotions to protect themselves from rejection by their significant others. These findings confirmed previous research showing that people who suffer from life threatening conditions may face a self-threatening dilemma (Silver, Wortman \& Crofton, 1990): They feel the need to communicate their distress in order to incite others to provide social support, but at the same time, they run the risk of receiving negative responses from others when they express their suffering.

Social constraints (individuals' perception that others are unreceptive to hearing about their negative experience) linked to emotional disclosure in chronic diseases have 


\section{SOCIAL SHARING OF EMOTIONS IN HIV/AIDS}

been thoroughly examined: for example, social constraints linked to cancer (Lepore \& Revenson, 2007) and linked to diabetes management (Braitman, et al., 2008). Likewise, previous research has been attentive to emotional distress in chronic conditions. For instance, studies have focused on emotional distress among diabetes patients (Snoeck et al., 2000; DeCoster, 2003). Moreover, difficulties in the verbalization of emotions have been found among some diabetes patients (Luminet et al., 2006).

Progress in anti-retro-viral (ARV) medication has led to the consideration of HIV/AIDS as a chronic illness (Kelly et al., 1998). However, stigma, social rejection and isolation still characterize HIV/AIDS infection. Previous studies have evidenced the difficult challenge faced by these patients when coping with negative emotions linked to the HIV/AIDS experience (Siegel \& Schrimshaw, 2000). Moreover, individuals living with an HIV/AIDS condition experience the loss of social support and are rejected by their social network (Muma et al., 1995), which can result in isolation. Such social and emotional burdens can result in negative outcomes. To illustrate, Gore-Felton et al. (2002) have evidenced an association of social support and of emotion focused coping strategies with risky sexual behaviours in HIV-positive men and women. HIV/AIDS is thus a chronic illness suitable to an investigation from the perspective of SSE and social constraints.

Prior research conducted with HIV/AIDS populations (Bigner \& Bozzet, 1989; Doll et al., 1994; Moneyham et al., 1996; Derlega et al., 2002) has shown that these patients fear others' negative responses. For example, Derlega et al. (2002) observed an association between a heightened perception of HIV-related stigma and the anticipation of potential negative consequences of disclosing the HIV diagnosis to a friend or a parent (ex., fear of rejection). Even though individuals facing different chronic conditions or diseases can experience stigmatisation (Van Brakel, 2006; Jones et al., 


\section{SOCIAL SHARING OF EMOTIONS IN HIV/AIDS}

1984), stigmatising responses vary from one condition to another. Few modern illnesses have been as widely stigmatised as HIV/AIDS: despite the extensive mass-media and health campaigns, a fear of being infected with HIV through mere social interactions as well as the association of HIV to death, still remain (Black \& Miles, 2002). Therefore, in the particular case of HIV/AIDS, contagiousness (Dijker, Koomen \& Kok, 1997; Dijker \& Raeijmaekers, 1999) of the disease and personal responsibility (Weiner, Perry \& Magnusson, 1998) associated to the sexual transmission of the disease, are specific factors that determine others' reactions to infected people. Therefore, perceived contagiousness, perceived seriousness, personal responsibility and norm-violating behaviours often associated with HIV infection colour HIV/AIDS related stigma (Bos et al., 2008).

For instance, an important dimension of stigmas is the degree to which they can be concealed from others (Jones et al., 1984). In the case of HIV, even though the visibility of the stigma relies upon disease progression and symptoms, concealing serostatus can be an option for these patients (e.g. Black \& Miles, 2002). A previous study (Frabble et al., 1998) suggested that when compared to individuals facing a visible stigma (ex. overweight), those facing a concealable stigma (ex. sexual orientation) were found to show more anxiety, depression, and negative affect, and less self-esteem.

Along another line, Fife and Wright (2000) compared the dimensionality of stigma and its impact on the self in Cancer patients and in HIV/AIDS patients. They found HIV infected persons to report higher feelings of social rejection, internalised shame and social isolation. In a similar vein, Fernandes et al. (2007), compared laypersons' stigma perception towards patients having Epilepsy, AIDS or Diabetes, and found AIDS to be the most stigmatised disease and Diabetes the least one. 


\section{SOCIAL SHARING OF EMOTIONS IN HIV/AIDS}

To our knowledge, studies have not yet compared different chronic conditions with respect to emotional inhibition linked to the perception of social responses (e.g., social constraints, self-disclosure, secrecy). The investigation reported in this article finds its roots in previous findings concerning difficulties with SSE amongst chronic illness patients (Herbette \& Rimé, 2004) and emotional inhibition of illness resulting from the perception of others' negative responses (e.g., Lepore \& Revenson, 2007). Yet, we hypothesized that the social aspects (ex. stigma, reject, isolation and ostracism) specific to this sexually transmitted infectious disease would differentiate HIV/AIDS patients with regard to SSE variables when compared to other (non-contagious) chronic illness patients such as diabetics and cancer patients.

Do HIV/AIDS patients manifest distinguishing traits in the inhibition of illness and non-illness related emotions? This study's main objective was to examine the differences in SSE between HIV/AIDS, diabetes and cancer patients. Previous findings have evidenced low illness disclosure levels among HIV/AIDS patients as well as HIV/AIDS patients' fears concerning others' negative responses (e.g., Derlega et al., 2002). We thus hypothesised that when compared to diabetes and cancer patients, HIV/AIDS patients would share less their illness related emotions. Furthermore, it was hypothesized that the HIV/AIDS group would differ from the comparison groups for negative emotions: for instance, HIV/AIDS patients would experience greater shame (Fife \& Wright, 2000).

As a result of the predicted heightened inhibition of illness-related emotions in HIV/AIDS patients, we expect two potential consequences. On the one hand, we hypothesize that when compared to diabetes and cancer patients, HIV/AIDS patients experience an excess of cognitive manifestations such as intrusive thoughts, mental rumination, and search for meaning. Evidence has shown that secrecy involves active 


\section{SOCIAL SHARING OF EMOTIONS IN HIV/AIDS}

inhibition and suppression of thoughts and feelings (e.g., Pennebaker, 1989; Kelly, 2002). For instance, Finkenauer and Rimé (1998) found that when compared to shared emotional events, non-shared emotional events resulted in greater search for meaning efforts to understand what happened, as well as in greater feelings of shame. On the other hand, the numerous social threats linked to HIV/AIDS, together with their inhibited sharing of the illness experience, leads us to expect that these patients should report reduced social support and a lower social integration.

\section{Method}

Participants

The following study was conducted in the Dominican Republic: 35 HIV/AIDS outpatients, 35 diabetes outpatients and 34 cancer outpatients were matched in age, gender and educational level. Table 1 displays the various characteristics of participants by group: age, sex, educational level, time of diagnosis and marital status. Marital status was not considered in the matching criteria, yet, no significant differences were found between the three groups $\left(\chi^{2}(104,2)=3.13\right.$; NS). As to time of diagnosis, when measured in months, significant differences were found $\left(F(2,101)=11.85 ; p<0.01 ; \eta^{2}=\right.$ 0.19). Post Hoc Tests $(\mathrm{p}<0.01)$ manifested that the cancer group $(\mathrm{M}=20.62 ; \mathrm{SD}=$ 26.88) significantly differed from both the HIV/AIDS group $(M=66.40 ; \mathrm{SD}=64.89)$ and the diabetes group $(\mathrm{M}=84.44 ; \mathrm{SD}=84.43)$.

All HIV/AIDS patients were under ARV medication, a precondition for enrollment in this study. The mean CD4 count in the sample was 233.20 (cells $/ \mathrm{mm}^{3}$ ) measured on average 5.27 months before the study. Within the HIV/AIDS group, 97.14\% $(\mathrm{N}=34)$ of patients reported having been infected with HIV through heterosexual sexual intercourse, and the remaining $2.85 \%(\mathrm{~N}=1)$ reported having been infected with HIV through homosexual sexual intercourse. 


\section{SOCIAL SHARING OF EMOTIONS IN HIV/AIDS}

As to diabetes patients, $62.86 \%$ of them were undergoing treatment with insulin injections and the remaining $37.14 \%$ were not insulin dependent. Information on the type of diabetes diagnosis was not assessed. Within the cancer group, $44.12 \%$ were undergoing chemotherapy, $11.76 \%$ radiotherapy, $38.23 \%$ both chemotherapy and radiotherapy, and the remaining 5.88\% were not undergoing any treatment. Within this group, all women $(\mathrm{N}=20 ; 58.82 \%$ of the cancer sample $)$ had a breast cancer diagnosis. As to the remaining $41.18 \%$ of the sample (male participants), $5.88 \%$ were diagnosed with lymphoma, $14.70 \%$ had a colon cancer diagnosis, $5.88 \%$ were diagnosed with prostate cancer, and $14.70 \%$ were diagnosed with other types of cancer.

The existence of a certain level of heterogeneity in this sample can be argued. For instance, the types of cancer diagnosis and treatments as well as in the type of diabetes diagnoses vary within these illness groups. However, it is important to recognize the difficulties that can be encountered when conducting this type of research. For example, it can be difficult to respect matching criteria (e.g. HIV/AIDS populations can be quite young when compared to Cancer populations).

\section{Insert Table 1 about here.}

\section{Procedure}

Patients were sampled in six different health care institutions: HIV/AIDS patients in two different HIV units belonging to the National HIV/AIDS Control Program of the Dominican Republic's Ministry of Health, Diabetes patients in a non-lucrative diabetes clinic, and cancer patients in two private non-lucrative oncology clinics and in one private oncology clinic. Previous authorization was obtained from the pertaining direction board for each institution.

A doctor, nurse or other medical staff informed patients about the study and proposed volunteer participation. Patients were informed that it consisted of research 


\section{SOCIAL SHARING OF EMOTIONS IN HIV/AIDS}

concerning emotional expression in chronic diseases, as part of an international university research program. The length of the interviews (approximately 40 minutes) and their confidentiality were announced. If patients volunteered, the researcher met with the patient. Respondents did not receive any kind of compensation for their participation. Informed consent was obtained from all participants.

Questionnaires were administered in an interview modality to ensure comprehension, only the researcher and the patient were present at the time of the interview. One single researcher interviewed all patients at the different health care institutions. Interviews took place in doctors' examination rooms or at the waiting rooms before or after patients' medical appointments.

\section{Measures}

A questionnaire (in Spanish) was administered. Most measures consisted of items to be rated upon likert scales. Some items were developed in Spanish for this study, others consisted of existing SSE measures that were translated from French into Spanish, and an existing Spanish validation was used for the social support measure. One of the researchers, fluent in Spanish and French translated the items. The final version of the entire questionnaire was reviewed by three Dominican lay-individuals to ensure the conceptual meaning of each question.

General Information was obtained through questions concerning age, sex, level of education (last level reached) and marital status.

Illness history, perception, emotional and cognitive impact were obtained. Some open questions assessed information about patients' illness history: time of diagnosis, time of treatment, and type of treatment. For the HIV/AIDS group, the last CD4 count was obtained from medical records under patients' consent. 


\section{SOCIAL SHARING OF EMOTIONS IN HIV/AIDS}

Patients' perception of others' negative evaluation of the illness was assessed.

Four items, to be rated upon likert scales ( $1=$ not at all; $5=$ extremely), were developed to evaluate patients' perceptions of others' responses when disclosing about their illness: (1) fear of rejection (I rather not talk about my illness and my illness related emotions so that others do not reject me); (2) lack of understanding of the illness and illness-related experiences (I have the feeling that people around me are not capable of understanding my illness and what I am going through); (3) fear of indiscretion (I fear that if I speak about my illness and my illness related emotions with those around me, they will be indiscreet about my personal and intimate information); (4) fear to reflect a negative image of the self (If I speak about my illness and my illness-related emotions, others will perceive a negative image of me).

Furthermore, two questions ( $\alpha=0.72$ ) were developed to assess patients' own perception of illness severity: (1) How sick do you feel, (2) Does your illness disturb your daily life? (1=not at all; 5=extremely). Illness-related negative emotions were assessed through 6 items developed for the current study. Participants were asked to answer on a 5-point scale $(1=$ not at all; $5=$ very much $)$ to what extent their illness caused in them: anxiety, worry, fear, anger, guilt and shame (e.g. When I think about my illness I feel shame).

As to illness-related cognitive manifestation, scores for mental rumination, intrusive thoughts and search of meaning were obtained by averaging scores for each of these three aspects of cognitive manifestations of the illness. A total of 10 items were translated into Spanish, and were scattered as follows: (1) three items (Zech \&Rimé, $2005)$ assessed mental rumination ( $\alpha=0.82$; Ex: During the past week, have you had through your mind thoughts, images, memories about your illness?; $1=$ not at all; $5=$ very much), (2) two items (Zech \&Rimé, 2005) assessed intrusive thoughts $(\alpha=0.71 ; E x$ : 


\section{SOCIAL SHARING OF EMOTIONS IN HIV/AIDS}

During the past week I have tried not to think about my illness; $1=$ not at all; $5=$ very much), and (3) five items (Finkenauer \& Rimé, 1998) assessed the search for meaning $(\alpha=0.86$; Ex: Today, when I think about my illness I feel the need to understand why and how?).

\section{Disclosure of diagnosis and Social sharing of illness related emotions were}

assessed. To estimate diagnosis disclosure, an open response item was developed asking participants to mention the number of people to whom they had disclosed their diagnosis.

Participants' beliefs about benefits resulting from SSE were assessed through five items ( $\alpha=0.83$; Herbette $\&$ Rimé, 2004) translated from French to Spanish. Patients were asked to rate on a 6 -point likert scale $(1=$ not at all; $6=$ very much $)$ to what extent they believed SSE to be beneficial: (1) to others, (2) to themselves, (3) to the person who shares the emotions, (4) to the person who listens to others' emotions, (5) to themselves when sharing illness-related emotions.

In addition, five items (Rimé et al., 1991) assessed aspects of SSE specific to illness-related emotions: (1) desire to share illness-related emotions (During the past week, to what extent, have you felt the desire to share your illness-related emotions and feelings?; 1=not at all; 5=very much); (2) frequency of SSE during the previous week (During the past week, how frequently have you shared your illness-related emotions and feelings?; 1=not at all; 5=very much); (3) number of sharing partners during the previous week (During the past week, with how many different people have you shared your illnessrelated emotions and feelings?); (4) number of sharing partners during the previous month (During the past month, with how many different people have you shared your illnessrelated emotions and feelings?). One item assessed the SSE of non-illness related emotions (Usually, in your daily life, do you share with others your emotions and feelings not related to your illness?; $1=$ not at all; $5=$ very much). These items were translated from the 


\section{SOCIAL SHARING OF EMOTIONS IN HIV/AIDS}

original French version (Rime et al., 1991) and the wording was adapted to the illness context.

Lastly, three items $(\alpha=0.88)$, were developed to assess the non-sharing of illnessrelated emotions and emotional aspects kept secret. Participants rated their answers for the fallowing questions on 5-point scales (1=Not at all; 5=extremely): (1) Are there thoughts, feelings or emotions linked to your illness that you have never shared with anyone? (2) Are there thoughts, feelings or emotions linked to your illness that you do not want to share with anyone? (3) Do you deliberately avoid talking about your illness?

Social Integration was assessed through the three items of the Spanish short version (Basabe, 2003) of the Social Support Appraisals Scale (Vaux et al, 1986). Two other items assessed participants' satisfaction with their social support (In general, do you feel satisfied with the practical support that you receive from others? In general, do you feel satisfied with the emotional support that you receive from others?). These items were to be rated upon 5 point likert scales $(1=$ Not at all; $5=$ extremely; $\alpha=0.81)$.

Due to the important number of variables considered, as well as to the heterogeneity of measures of stigma linked to health (e.g. different measures for different diseases), it was decided to develop, in Spanish, a few items to evaluate patients' perceptions of others' stigmatising responses. Recently, Earnshaw and Quinn (2011) have addressed this issue. Therefore, four items $(\alpha=0.84)$, to be rated upon likert scales ( $1=$ Not at all; $5=$ extremely), were developed to assess participants' perception of social exclusion linked to the ill ness (e.g., To what extent do you feel rejected by others due to your illness?; To what extent do you feel alone due to your illness?).

\section{Results}

Illness perception, emotional and cognitive impact 
SOCIAL SHARING OF EMOTIONS IN HIV/AIDS

Patients' perception of others' negative responses when disclosing about their illness yielded a number of significant effects. MANOVA was carried out to evaluate group differences for the following set of variables: (1) fear of rejection, (2) lack of

understanding of the illness and illness-related experiences, (3) fear of others' indiscretion and (4) fear to reflect a negative image of the self. Results showed significant differences between the three groups for these four variables $(\mathrm{F}(8,196)=$ 13.73; $<<0.01 ; \eta_{\mathrm{p}}{ }^{2}=0.36$ ). Separate ANOVAs were then conducted in order to specify significant effects. Fear of rejection $\left(\mathrm{F}(2,101)=49.37 ; \mathrm{p}<0.01 ; \eta_{\mathrm{p}}{ }^{2}=0.49\right)$ was rated by the HIV/AIDS group $(\mathrm{M}=4.29 ; \mathrm{SD}=1.53)$ at a higher level than both comparison groups (diabetes: $\mathrm{M}=1.97 ; \mathrm{SD}=1.60$; cancer: $\mathrm{M}=1.17$; $\mathrm{SD}=0.76$; Post Hoc: $\mathrm{p}<$ 0.01). The groups also differed significantly as to their perception of others' lack of understanding of their illness and their illness-related experiences $(F(2,101)=12.89 ; p$ $\left.<0.01 ; \eta_{\mathrm{p}}{ }^{2}=0.20\right)$. Post Hoc tests $(\mathrm{p}<0.01)$ showed that the HIV/AIDS group $(\mathrm{M}=$ $3.77 ; \mathrm{SD}=1.81)$ and the diabetes group $(\mathrm{M}=3.00 ; \mathrm{SD}=1.85)$ significantly differed from the cancer group $(\mathrm{M}=1.76 ; \mathrm{SD}=1.21)$ concerning the perception of others' lack of understanding. As to fear of others' indiscretion $\left(\mathrm{F}(2,101)=38.94 ; \mathrm{p}<0.01 ; \eta_{\mathrm{p}}{ }^{2}=\right.$ 0.44), the HIV/AIDS group $(M=4.43 ; \mathrm{SD}=1.36)$ reported a significantly higher fear than the diabetes $(M=2.06 ; \mathrm{SD}=1.57)$ and cancer $(\mathrm{M}=1.74 ; \mathrm{SD}=1.21)$ groups (Post Hoc: $\mathrm{p}<0.01)$. Finally, the HIV/AIDS group $(\mathrm{M}=3.86$; $\mathrm{SD}=1.59)$ manifested significantly higher scores for fear to reflect a negative image of themselves when talking about the illness $\left(\mathrm{F}(2,101)=30.47 ; \mathrm{p}<0.01 ; \eta_{\mathrm{p}}{ }^{2}=0.38\right.$; Post Hoc tests: $\mathrm{p}<0.01)$ when compared to both the diabetes $(\mathrm{M}=2.00 ; \mathrm{SD}=1.51)$ and the cancer $(\mathrm{M}=$ $1.32 ; \mathrm{SD}=1.01)$ groups.

The three groups differed as to patients' perception of illness severity $(\mathrm{F}(2,101)$ $\left.=8.88 ; \mathrm{p}<0.01 ; \eta_{\mathrm{p}}{ }^{2}=0.15\right)$. Post Hoc tests showed that the diabetes group $(\mathrm{M}=2.97$; 


\section{SOCIAL SHARING OF EMOTIONS IN HIV/AIDS}

$\mathrm{SD}=1.46)$ had higher scores than the cancer group $(\mathrm{M}=2.19 ; \mathrm{SD}=1.24 ; \mathrm{p}<0.05)$ and the HIV/AIDS group $(\mathrm{M}=1.69 ; \mathrm{SD}=1.13 ; \mathrm{p}<0.01)$.

Regarding negative illness-related emotions, MANOVA evidenced significant differences between the three groups for this vector of dependent variables $(\mathrm{F}(12.19)=$ 3.88; $\mathrm{p}<0.01 ; \eta_{\mathrm{p}}{ }^{2}=0.20$ ). Separate ANOVAs accompanied with Scheffe post hoc comparisons revealed the following effects. For fear, the cancer group $(\mathrm{M}=1.79 ; \mathrm{SD}=$ 1.37) showed significantly lower scores $\left(F(2,101)=4.25, \mathrm{p}<0.05 ; \eta_{\mathrm{p}}{ }^{2}=0.08\right.$; Post Hoc Tests: $\mathrm{p}<0.05)$ than the HIV/AIDS group $(\mathrm{M}=2.74 ; \mathrm{SD}=1.69)$ and the diabetes group $(\mathrm{M}=2.77 ; \mathrm{SD}=1.68)$. As to anger, the diabetes group $(\mathrm{M}=2.23 ; \mathrm{SD}=1.54)$ was found significantly higher $\left(\mathrm{F}(2,101)=4.34, \mathrm{p}<0.05 ; \eta_{\mathrm{p}}{ }^{2}=0.08\right.$; Post Hoc: $\left.\mathrm{p}<0.05\right)$ than the cancer group $(\mathrm{M}=1.30 ; \mathrm{SD}=0.88)$. For guilt, the HIV/AIDS group $(\mathrm{M}=2.86$; $\mathrm{SD}$ $=1.90)$ showed significantly higher scores $\left(F(2,101)=6.08, \mathrm{p}<0.0 ; \eta_{\mathrm{p}}{ }^{2}=0.11\right)$ than the cancer group $(\mathrm{M}=1.53 ; \mathrm{SD}=1.05 ;$ Post Hoc: $\mathrm{p}<0.01)$. As for shame $(\mathrm{F}(2,101)=$ 12.94, $\mathrm{p}<0.01, \eta_{\mathrm{p}}{ }^{2}=0.20$; Post Hoc Tests: $\left.\mathrm{p}<0.01\right)$, the HIV/AIDS group $(\mathrm{M}=3.00$; SD $=1.89)$ significantly showed higher scores, differing from both the diabetes $(\mathrm{M}=1.86$; $\mathrm{SD}=1.46)$ and cancer $(\mathrm{M}=1.24 ; \mathrm{SD}=0.82)$ groups. No significant differences were found between the three groups concerning anxiety $(\mathrm{F}(2,101)=2.95 ; \mathrm{NS})$.

MANOVA, conducted for the three aspects of illness-related cognitive manifestations, yielded no significant group differences $(F(6,198)=1.65 ; \mathrm{NS})$.

\section{Disclosure of diagnosis and social sharing of illness related emotions}

Significant differences were found among the three groups for patients' disclosure of their diagnosis. The HIV/AIDS group reported a smaller number of people to whom they had disclosed their diagnosis $\left(\chi^{2}(104,2)=41.23 ; \mathrm{p}<0.01\right)$. Thus, $93.94 \%$ of diabetes patients and $96.88 \%$ of cancer patients reported having disclosed their 


\section{SOCIAL SHARING OF EMOTIONS IN HIV/AIDS}

diagnosis to more than ten people; whereas only $32.14 \%$ of HIV/AIDS patients reported having done so.

Concerning the beliefs about beneficial consequences of SSE, the HIV/AIDS group $(M=2.61 ; S D=1.30)$ evidenced significantly lower scores $(F(2,101)=13.81$; $\left.\mathrm{p}<0.01 ; \eta_{\mathrm{p}}{ }^{2}=0.21\right)$ when compared to the diabetes $(\mathrm{M}=4.13 ; \mathrm{SD}=1.42)$ and the cancer $(\mathrm{M}=4.11 ; \mathrm{SD}=1.43)$ groups (Post Hoc Tests: $\mathrm{p}<0.01)$

\section{Insert Table 2 about here.}

Table 2 displays the various results pertaining to the social sharing of illnessrelated emotions for the three groups. MANCOVA (co-variants: guilt, shame, diagnosis disclosure and time of diagnosis) was carried out on three of the relevant items expected to vary in the same direction: (1) frequency of emotion sharing, (2) number of sharing partners during the week preceding the study and (3) number of sharing partners during the month are preceding the study. Results evidenced significant differences between the three groups $\left(\mathrm{F}(6,182)=4.17 ; \mathrm{p} \leq 0.01 ; \eta_{\mathrm{p}}{ }^{2}=0.12\right)$. ANCOVA results showed that HIV/AIDS respondents had shared their illness-related emotions less frequently $\left(\mathrm{F}(2,93)=9.30 ; \mathrm{p}<0.01 ; \eta_{\mathrm{p}}{ }^{2}=0.17\right)$ and with a lower number of partners during the week preceding the study $\left(F(2,93)=8.49 ; \mathrm{p}<0.01 ; \eta_{\mathrm{p}}{ }^{2}=0.15\right)$ when compared to both the diabetes group and the cancer group (Post Hoc tests: $\mathrm{p}<0.01$ ). They had also shared these illness-related emotions with a lower number of sharing partners during the month preceding the study $\left(\mathrm{F}(2,93)=10.96 ; \mathrm{p} \leq 0.01 ; \eta_{\mathrm{p}}{ }^{2}=0.19\right)$ when compared to both comparison groups (Post Hoc tests: $\mathrm{p}<0.01$ ). Notably, no significant differences were found between the three groups regarding the social sharing of non-illness related emotions $(\mathrm{F}(2,93)=1.75 ; \mathrm{NS})$.

Likewise, ANCOVA (co-variants: guilt, shame, diagnosis disclosure and time of diagnosis) results confirmed the group effect for the non-sharing of illness-related 


\section{SOCIAL SHARING OF EMOTIONS IN HIV/AIDS}

emotions $\left(F(2,93)=6.00 ; \mathrm{p} \leq 0.01 ; \eta_{\mathrm{p}}{ }^{2}=0.11\right)$. This analysis showed that the HIV/AIDS group scored significantly higher for the non-sharing of illness-related emotions when compared to the diabetes and to the cancer groups (Post Hoc tests: $p<$ 0.01; See Table 2). The three groups were found at comparable levels as to their desire to share their illness-related emotions $(\mathrm{F}(2,93)=1.99 ; \mathrm{NS})$.

\section{Social Integration}

No significant differences were found between the three groups in the perception of social support and social integration $(F(2,96)=1.61$; NS) when controlling for diagnosis disclosure. As to perceived social exclusion, ANCOVA (co-variant: diagnosis disclosure) was carried out and yielded a significant group effect $(\mathrm{F}(2,96)=$ $\left.6.12 ; \mathrm{p}<0.01 ; \eta_{\mathrm{p}}^{2}=0.11\right)$. Post Hoc tests $(\mathrm{p}<0.01)$ showed that the HIV/AIDS group $(\mathrm{M}=1.68 ; \mathrm{SD}=1.02)$ had significantly higher scores for perceived social exclusion when compared to the cancer group $(\mathrm{M}=1.06 ; \mathrm{SD}=0.21)$.

\section{Discussion}

Chronic illness patients encounter inhibition and constraints in the social sharing of their illness-related emotions (Herbette \& Rimé, 2004; Lepore \& Revenson, 2007). Expressing one's suffering and disclosing one's life-threatening condition can elicit negative responses from healthy others. We hypothesized that among chronically ill patients, those suffering from HIV/AIDS would be particularly at risk of experiencing negative social responses. HIV/AIDS, involving stigmatizing information and a linkage to sexual behaviour, is most likely to be kept concealed (Kelly, 2002). Furthermore, since HIV is a contagious disease, it represents a health threat to healthy others, therefore eliciting negative reactions (Bos et al., 2008). We thus expected that compared to other patients suffering a chronic illness, HIV/AIDS patients would manifest a distinctive propensity of holding back their need to socially share their 


\section{SOCIAL SHARING OF EMOTIONS IN HIV/AIDS}

illness-related emotions. Our study comparing HIV/AIDS patients to diabetes and cancer patients yielded abundant support to these predictions.

We found that HIV/AIDS patients rated their illness as less severe. In spite of this, they were more concerned by other persons' negative perception of their illness than did the comparison groups. They expressed a higher apprehension that disclosing their illness experience would (1) reflect a negative image of them, (2) entail their social rejection, and (3) expose them to a lack of discretion of their listeners. These results are congruent with other studies evoked in the introduction showing HIV/AIDS patients to fear others' negative responses. Such observations concur to expect that these multiple external threats perceived HIV/AIDS patients affect negatively their social sharing of illness-related emotions. Motives in this regard resulted from internal sources. HIV/AIDS patients differed markedly from the other two groups regarding illnessrelated emotions: they manifested higher guilt and shame. Past research demonstrated that shame, guilt and self-attribution of responsibility constitute as factors proper to favor emotional secrecy (Kelly, 2002; Finkenauer \& Rimé, 1998). Thus, altogether with the social ones, these emotional and cognitive factors should concur in affecting HIV/AIDS patients' sharing of their illness-related feelings.

The expected consequences were largely supported by this study's findings. HIV/AIDS patients in this study disclosed their diagnosis much less than did cancer and diabetes patients. Moreover, the direct assessment of the social sharing of illness-related emotions revealed three remarkable facts. First, HIV/AIDS patients were perfectly comparable to diabetes and cancer patients for their usual SSE unrelated to their illness. They thus respond to the general principle of the SSE in the same way as do other people. Second, HIV/AIDS expressed as much need to share their illness-related emotions as the two comparison groups. They thus clearly want as much as other 


\section{SOCIAL SHARING OF EMOTIONS IN HIV/AIDS}

chronic patients to share emotions resulting from their illness condition. Third, in sharp contrast with the two previous observations, HIV/AIDS patients differed markedly for the social sharing of their illness-related emotions. They shared these emotions at a much lower frequency and with a much lower number of persons. In sum, many elements confirmed HIV/AIDS patients to experience a constrained sharing of their illness experience. Thus, if a chronic illness exposes patients to social constraints and to a contained sharing of illness-related emotions (Herbette \& Rimé, 2004; Lepore \& Revenson, 2007), the present study revealed HIV/AIDS patients to be particularly underprivileged in this regard.

On the one hand, it was expected that as a result of the predicted non-sharing of illness-related emotions, HIV/AIDS patients would experience more mental ruminations, intrusive thoughts and search for meaning. A known paradoxical result of the suppression of thoughts or feelings is the rebound effect. The very state of mind one had thought to avoid, tends to impose itself forcefully thereafter (see Wentzlaff \& Wegner, 2000 for a review). However, this prediction was not supported. On the other hand, the numerous social threats HIV/AIDS patients fear, together with the inhibited sharing of their illness experience, supported the expectation that these patients would report reduced social support and lower social integration. This prediction was only partially sustained. HIV/AIDS patients did not differ for perceived social support. However, they rated themselves higher for social exclusion.

How can we account for these partially negative findings with respect to our two hypotheses? One possibility is that even if HIV/AIDS patients limit the sharing of their illness-related emotions, they nevertheless find around themselves enough listening for their illness-related emotions. In this manner, they would avoid the cognitive consequences of a rebound effect likely to follow from a total lack of sharing. Finding 


\section{SOCIAL SHARING OF EMOTIONS IN HIV/AIDS}

enough listening would also lead these patients to perceive the social support they receive as relatively satisfactory. The socio-cultural context in which the present study was conducted might play some role in this regard. In the Dominican Republic, family ties are of particular importance. The family forms the basis of stability and the individual derives a social network and assistance in times of need from the extended family which generally encompasses three generations. Loyalty to the family comes before any other social relationship. In such a socio-cultural context, it is possible that HIV/AIDS patients receive more attention, help and support from their closer family circle than would be the case in more individualistic cultures. Thus, the numerous threats these patients perceive from the disclosure of their illness might regard their broader social network only and might thus be less consequential for the emotional, cognitive and social variables examined here.

Future studies might profitably compare the social situation of HIV/AIDS patients across individualistic and communal socio-cultural contexts. Likewise, future research can benefit from inter and intra disease comparisons regarding patients' perceptions of negative social responses. For example, differences concerning diabetes linked to obesity and diabetes mellitus, where causal and self-blame attributions can vary. The same could be explored among different cancer diagnosis and treatments or among HIV/AIDS patients with different infection modes.

Nonetheless, it still remains that HIV/AIDS patients in this study reported higher feelings of social exclusion. Even if this would regard only their broader social circle, HIV/AIDS patients might incur damaging consequences form such a situation. Previous studies demonstrated that a lower social integration is associated with a higher mortality (Bekman \& Syme, 1979; House et al., 1982). Social integration is considered a major risk factor for morbidity and mortality, and the level of risk involved was shown to 


\section{SOCIAL SHARING OF EMOTIONS IN HIV/AIDS}

parallel those of classic health risk factors such as obesity, sedentarity, and perhaps smoking (House et al., 1988). Future studies should thus assess effects of interventions focused upon the various emotions which were found to be distinctive for HIV/AIDS: fear of social threats, shame, and guilt. In parallel, intervention programs should aim at modifying the representation of HIV/AIDS among people living in geographic areas with important concentrations of patients.

\section{References}

Basabe, N. (2003). Salud, Factores Psico-sociales y Cultura. In D. Paéz, I. Fernández, S.Ubillos, \& E. Zubieta (Eds.), Psicología social, cultura y educación. Madrid: Pearson.

Berkman, L. F., \& Syme, S. L. (1979). Social networks, host resistance, and mortality: A nine-year follow-up study of Alameda County residents. American Journal of Epidemiology, 109, 186-204.

Bigner J. \& Bozzet F.W. (1989). Parenting by Gay fathers. Marriage and Family Review, 14, 155-175.

Black, B. P., \& Miles, M. S. (2002). Calculating the risks and benefits of disclosure in African American women who have HIV. Journal of Obstetric, Gynecologic \& Neonatal Nursing, 31(6), 688-697.

Bos, A.E.R, Schaalma, H.P. \& Pryor, J.B. (2008). Reducing AIDS-related stigma in deveopping countries: The importance of theory- and evidence-based inverventions. Psychology, Health \& Medecine, 13 (4): 450-460.

Braitman, L.A., Derlega, J., HEnson, J.M, Robinet, I ., Saadeh, G.M., Janda, L.J., Hixton, M. \& Miranda, J., (2008). Social COnstraints in talking about diabetes to significant others and diabetes self-care : a social-cognitive processing perspective. Journal of Social and Clinical Psychology, 27(9), 949-969. 


\section{SOCIAL SHARING OF EMOTIONS IN HIV/AIDS}

\section{Christophe, V. \& Rimé, B. (1997). Exposure to the social sharing of emotion:}

Emotional impact, listener responses and the secondary social sharing. European Journal of Social Psychology, 27, 37-54.

DeCoster V.A. (2003). The emotions of adults with diabetes: a comparison across race. Social Work Health Care, 36, 79-99.

Derlega , V., Winstead, B., Greene, K., Serovich, J. \& Elwood, W. (2002). Perceived HIV-related Stigma and HIV disclosure to Relationship Partners after finding out about the Seropositive Diagnosis. Journal of Health Psychology, 7(4): 415432.

Dijker, A.J., Koomen, W. \& Kok, G. (1997). Interpersonal determinants of fear of people with AIDS: The moderating role of predictable behavior. Basic and Applied Social Psychology, 19, 61-79.

Dijker, A.J. \& Raeijmaekers, F. (1999). The influence of seriousness and contagiousness of disease on emotional reactions to ill persons. Psychology and Health, 14, 131-141.

Doll L.S., Harrison, J.S., Frey, R.L., McKirnan D., Bartholow B.N., Douglas J.M., Joy D., Bolan, G. \& Doetsch J. (1994). Failure to disclose HIV risk among gay and bisexual men attending sexually transmitted disease clinics. American Journal of Preventive Medicine, 10, 125-129.

Earnshaw, V.A. \& Quinn, D.M. (2001). The impact of stigma in healthcare on people living with chronic illnesses. Journal of Health Psychology, 17 (2) 157- 168.

Fernandes P.T., Salgado P.C., Noronha A.L., Barbosa, F.D., Sousa, E.A., \& Sander, J. (2007). Prejudice towards chronic diseases: comparison among AIDS, diabetes and epilepsy. Seizure, 16, 320-3. 


\section{SOCIAL SHARING OF EMOTIONS IN HIV/AIDS}

Fife, B.L. \& Wright, E. R. (2000). The Dimensionality if Stigma: A Comparison of its impact on the Self of Persons with HIV/AIDS and Cancer. Journal of Health and Social Behavior, 41, 50-67.

Finkenauer, C., \& Rimé, B. (1998). Socially shared emotional experiences vs. emotional experiences kept secret: Differential characteristics and consequences. Journal of Social and Clinical Psychology, 17, 295-318.

Frable, D. E. S., Platt, L., \& Hoey, S. (1998). Concealable stigmas and positive selfperceptions: Feeling better around similar others. Journal of Personality and Social Psychology, 74(4), 909-922.

Gore-Felton, C., Koopman, C., Turner-Cobb, J.M., Duran, R., Israelski, D., \& Spiegel, D. J. (2002). The Influence of Social Support, Coping and Mood on Sexual Risk Behavior among HIV-Positive Men and Women. Journal of Health Psychology, 7 (6), 713-722.

Herbette, G. \& Rimé, B. (2004). Verbalization of emotion in chronic pain patients and their psychological adjustments.Journal of Health Psychology, 9, 661-676.

House J.S., Robbins C, \& Metzner H. (1982). The association of social relationships and activities with mortality: Prospective evidence from the Tecumseh community health study. American Journal of Epidemiology, 116, 123-140.

House, J.S., Landis, K.R. \& Umberson, D. (1988). Social relationships and health. Science, 241:4865, 550-545.

Jones E.E., Farina A., Hastorf, A.H., Markus H., Miller D.T. \& Scott R.A. (1984). Social Stigma: The Psychology of Marked Relationships. New York: Freeman.

Kelly, A. (2002). The Psychology of Secrets, New York, Plenum Publishers.

Kelly, J.A., Otto-Salaj, L.L., Sikkema, K.J., Pinkerton, S.D. \& Bloom, F.R. (1998). Implications of HIV treatment advances for behavioral research on AIDS: 


\section{SOCIAL SHARING OF EMOTIONS IN HIV/AIDS}

protease inhibitors and new challenges in HIV secondary prevention. Health Psychology, 17, 310-319.

Lepore, S.J. \& Revenson, T.A. (2007). Social Constraints on Disclosure and Adjustment to Cancer. Social and Personality Psychology Compass, 1(1), 313-333.

Lepore, S.J., Ragan, J.D., \& Jones, S. (2000). Talking facilitates cognitiveemotional processes of adaptation to an acute stressor. Journal of Personality and Social Psychology, 78, 499-508.

Lepore, S. J., \& Helgeson,V. (1998). Social constraints moderate the relation between intrusive thoughts and mental health in prostate cancer survivors. Journal of Social and Clinical Psychology, 17, 89-106.

Luminet, O., de Timary, P., Buysschaert, M., \& Luts A. (2006)The Role of alexithymia factors in glucose control of persons with type 1 diabetes : a pilot study, 2006, Diabetes \& metabolism, 32(5): 417-424.

Moneyham L., Seals B., Demi A., Sowell R., Cohen L. \& Guillory J. (1996). Experiences of disclosure in women infected with HIV. Health Care for Women International, 17, 209-221.

Muma R.D., Ross M.W., Parcel G.S. \& Pollard R.B. (1995). Zidovuline adherence among individuals with HIV infection. AIDS Care, 7, 391-405.

Nils, F., \& Rimé, B. (2012). Beyond the myth of venting: Social sharing modes determine emotional and social benefits from distress disclosure. European Journal of Social Psychology. doi: 10.1002/ejsp.1880.

Panagopoulou, E., Rime, B., Maes, S., \& Montgomery, A.J. (2006). Social Sharing of Emotion in Anticipation of Cardiac Surgery: Effects on Preoperative Distress. Journal of Health Psychology, 11, 809-820. 


\section{SOCIAL SHARING OF EMOTIONS IN HIV/AIDS}

Pennebaker, J. W. (1989). Confession, inhibition, and disease. In L. Berkowitz (Ed.), Advances in Experimental social psychology (Vol. 22, pp. 211-244). New York: Academic.

Rimé, B. (2009). Emotion Elicits the Social Sharing of Emotion: Theory and Empirical Review. Emotion Review, 1(1): 60-85.

Rimé, B. (2005). Le partage social des émotions [The Social Sharing of Emotions]. Paris : Presses Universitaires de France.

Rimé, B., Mesquita, B., Philippot, P., \& Boca, S. (1991). Beyond the emotional event: Six studies on the social sharing of emotion. Cognition and Emotion, 5, $435-465$.

Rimé, B., Philippot, P., Boca, S., \& Mesquita, B. (1992). Long lasting cognitive and social consequences of emotion: Social sharing and rumination. In W. Stroebe \&M. Hewstone (Eds.), European review of Social Psychology, 3, 225258.

Rimé, B., Finkenauer, C., Luminet, O., Zech, E., \& Philippot, P. (1998). Social sharingof emotion: New evidence and new questions. In W. Stroebe \& M. Hewstone (Eds.), European review of social psychology, 9, 145-189.

Siegel, K., \& Schrimshaw, E.W. (2000). Coping with Negative Emotions: The Cognitive Strategies of HIV-infected Gay/Bisexual Men. Journal of Health Psycholy, 5(4), 517-530

Silver, R.C., Wortman, C.B. \& Crofton, C. (1990). The role of coping in support provision: the self-presentational dilemma of victims of life crises. In I.G. Sarason, I. G., Sarason, B. R. \& Pierce, G. R. (Eds), Social Support: An interactional view. New York: Wiley. 


\section{SOCIAL SHARING OF EMOTIONS IN HIV/AIDS}

Snoek F.J., Pouwer F., Welch G.W., \& Polonsky, W.H. (2000). Diabetes-related emotional distress in Dutch and U.S. diabetic patients: cross-cultural validity of the Problem Areas in Diabetes Scale. Diabetes Care, 23, 1305-1309.

Sydor, G., Philippot, P., (1996). Conséquences psychologiques des massacres de 1994 au Rwanda [Psychological consequences of the 1994 massacre in Rwanda]. Santé Mentale au Québec, 21, 229-246.

Tagney, J. (1991). Moral affect: the good, the bad and the ugly. Journal of Personality and Social Psychology, 61, 598-607.

Tagney, J.P. \& Dearing, R.L. (2002). Shame and Guilt, New York, Guilford Press.

Van Brakel, W.H. (2006). Measuring health-related stigma: a literature review. Psychology, health \& medicine, 11(3): 307-334.

Vaux, A., Phillips, J., Holly, C., Thomson, B., Williams, D \& Stewart, D. (1986): The social support appraisals (SSA) scale: studies of reliability and validity. American Journal of Community Psychology, 14, 195-219.

Wegner, D.M. (1994). Ironic processes of mental control. Psychological Review, 101, $34-52$

Weiner, B., Perry, R. B. \& Magnusson, J. (1998). An attributional analysis of reactions to stigmas. Journal of Personality and Social Psychology, 55,738-748.

Wenzlaff, R.M. \&,Wegner, D.M. (2000). Thought suppression. In: Fiske ST, editor. Annual review of psychology. Palo Alto, CA: Annual Reviews: 51, 5991.

Zech, E., \& Rimé, B. (2005) Is talking about an emotional experience helpful? Effects on emotional recovery and perceived benefits. Clinical Psychology and Psychotherapy, 12, 270-287. 


\section{SOCIAL SHARING OF EMOTIONS IN HIV/AIDS}

Table 1. Age, sex, educational level, time of diagnosis and marital status per group.

\begin{tabular}{|c|c|c|c|}
\hline VARIABLE & HIV/AIDS $(\mathrm{n}=35)$ & Diabetes $(n=35)$ & Cancer $(n=34)$ \\
\hline \multicolumn{4}{|l|}{ AGE } \\
\hline M & 42.09 & 41.77 & 42.91 \\
\hline SD & 11.24 & 11.27 & 12.00 \\
\hline \multicolumn{4}{|l|}{ SEX } \\
\hline Male & $45.71 \%$ & $45.71 \%$ & $41.18 \%$ \\
\hline Female & $54.29 \%$ & $54.29 \%$ & $58.82 \%$ \\
\hline \multicolumn{4}{|c|}{ EDUCATIONAL LEVEL } \\
\hline Elementary School & $68.57 \%$ & $77.14 \%$ & $70.59 \%$ \\
\hline High School & $11.43 \%$ & $14.29 \%$ & $17.62 \%$ \\
\hline Technical Degree & $5.71 \%$ & $5.71 \%$ & $2.94 \%$ \\
\hline University Degree & $8.57 \%$ & 0 & $2.94 \%$ \\
\hline No Diploma & $5.71 \%$ & $2.86 \%$ & $5.88 \%$ \\
\hline \multicolumn{4}{|l|}{ TIME DIAGNOSIS } \\
\hline$\leq 10$ years & $80 \%$ & $62.86 \%$ & $97.06 \%$ \\
\hline$\geq 10$ years & $20 \%$ & $37.14 \%$ & $2.94 \%$ \\
\hline \multicolumn{4}{|c|}{ MARITAL STATUS } \\
\hline Single & $54.29 \%$ & $37.14 \%$ & $37.14 \%$ \\
\hline In a couple & $45.71 \%$ & $62.87 \%$ & $35.29 \%$ \\
\hline
\end{tabular}




\section{SOCIAL SHARING OF EMOTIONS IN HIV/AIDS}

Table 2. Mean, Standard Deviation, ANCOVA results for the variables involving the social sharing of illness-related emotions.

\begin{tabular}{|c|c|c|c|c|c|}
\hline VARIABLE & GROUP & M(SD) & $F(2,93)$ & $\mathbf{p}$ & $\eta_{p}^{2}$ \\
\hline \multirow[t]{3}{*}{ Frequency of Emotion Sharing } & HIV/AIDS $(n=35)$ & $1.83(1.27)^{* *}$ & & & \\
\hline & Diabetes $(\mathrm{n}=35)$ & $3.49(2.59)$ & 9.30 & $\leq 0.01$ & 0.17 \\
\hline & Cancer $(n=34)$ & $4.74(2.59)$ & & & \\
\hline \multirow[t]{3}{*}{ Number of Sharing Partners Past week } & HIV/AIDS $(\mathrm{n}=35)$ & $1.94(1.41)^{* *}$ & & & \\
\hline & Diabetes $(\mathrm{n}=35)$ & $3.54(2.39)$ & 8.49 & $\leq 0.01$ & 0.15 \\
\hline & Cancer $(n=34)$ & $4.91(2.30)$ & & & \\
\hline \multirow[t]{3}{*}{ Number of Sharing Partners Past Month } & HIV/AIDS ( $\mathrm{n}=35)$ & $1.86(1.59)^{* *}$ & & & \\
\hline & Diabetes $(n=35)$ & $4.60(3.29)$ & 10.96 & $\leq 0.01$ & 0.19 \\
\hline & Cancer $(n=34)$ & $6.29(3.24)$ & & & \\
\hline \multirow{3}{*}{$\begin{array}{l}\text { Non-sharing of illness related emotions } \\
(\alpha=0.88)\end{array}$} & HIV/AIDS $(n=35)$ & $4.13(1.25)^{* *}$ & & & \\
\hline & Diabetes $(\mathrm{n}=35)$ & $2.43(1.53)$ & 6.00 & $\leq 0.01$ & 0.11 \\
\hline & Cancer $(\mathrm{n}=34$ & $2.16(1.63)$ & & & \\
\hline \multirow[t]{3}{*}{ Desire to share illness-related emotions } & HIV/AIDS $(\mathrm{n}=35)$ & $1.94(1.59)$ & & & \\
\hline & Diabetes $(\mathrm{n}=35)$ & $2.60(1.79)$ & 1.99 & NS & NS \\
\hline & Cancer $(\mathrm{n}=34)$ & $2.62(1.66)$ & & & \\
\hline
\end{tabular}

**Post Hoc evidences significant differences between the HIV/AIDS group and both Cancer and Diabetes groups. 